\title{
Urbanismo militar na "região olímpica": dinâmicas de produção do espaço para além dos megaeventos
}

Frank Andrew Davies ${ }^{1}$

\section{Resumo}

Este artigo explora parte dos resultados da investigação de doutorado realizada pelo autor dedicada às formas de governo e situações de disputa na preparação de Deodoro como uma das "regiões olímpicas" para os Jogos de 2016 sediados no Rio de Janeiro. Entre outras características, a localidade é marcada por intensa e dispersa presença das organizações do Exército Brasileiro, condensando ali o maior aquartelamento da América Latina. Em anos que antecederam o torneio, a proposta de criação de um "parque verde" em Realengo sob iniciativa de moradores organizados foi inviabilizada pelo comando militar responsável pela área pretendida, que, ao invés disso, apresentou um projeto de condomínio residencial a ser construído e vendido por fundação e bancos privados ligados ao Exército e geridos por superiores da corporação. De general para general, mudanças e disputas em torno do terreno revelaram dinâmicas possíveis de produção do espaço no contexto dos megaeventos, e que para além dele constituem parte da vida política brasileira contemporânea, marcada pela participação cada vez maior de agentes militares em posições de liderança na administração estatal.

\section{Palavras-chave}

Urbanismo militar. Produção do espaço. Conflitos urbanos.

\section{Abstract}

This article explores part of the results of the doctoral research conducted by the author, dedicated to the forms of government and situations of dispute in preparing Deodoro as one of the "Olympic Areas" for the Rio de Janeiro 2016 Olympic Games. Among other features, the locality is marked by the intense and dispersed presence of the Brazilian Army organizations, condensing there the largest military complex in Latin America. In the years leading up to the tournament, the proposed creation of a "green park" in Realengo under the initiative of organized residents was deemed unfeasible by the military command responsible for the intended area, which instead submitted a residential condominium project to be built and sold by private foundations and banks linked to the Army, run by corporation superiors. From general to general, changes and disputes around the terrain reveal possible dynamics of production of space in the context of mega-events and beyond it, constituting

\footnotetext{
${ }^{1}$ Professor da Universidade Estadual do Ceará. E-mail: daviesfr@gmail.com.
} 
part of contemporary Brazilian political life, marked by the increasing participation of military agents in leadership positions in state administration.

\section{Keywords}

Military urbanism. Production of space. Urban conflicts.

\section{Introdução}

Este artigo explora resultados da investigação de doutorado realizada pelo autor a respeito das formas de governo e situações de disputa na preparação de Deodoro como uma das "regiões olímpicas" para os Jogos de 2016, sediados no Rio de Janeiro (DAVIES, 2017). Considerando megaevento como "ocasião-chave" para produção de imagens e discursos sobre a cidade e o país-sede, amplificada pela proeminência internacional, o apelo dramático e o significado da ocasião para uma "cultura pública" (ROCHE, 2000), acompanhei dinâmicas que envolveram agentes da Prefeitura, comandos do Exército, empresas construtoras e moradores organizados na realização dessa localidade como um dos espaços de torneios e competições esportivas na cidade.

Para compreender as dinâmicas que produzem essa "região olímpica", é importante levar em conta a presença intensa de organizações do Exército Brasileiro nesse bairro e em áreas vizinhas, condensando ali o maior aquartelamento da América Latina. Quartéis, batalhões, regimentos, vilas residenciais, muros, arames e guaritas são marcas do urbanismo ${ }^{2}$ de tipo militar, que nessa região da cidade se faz contígua a casarios simples representados no imaginário da cidade como "subúrbio carioca". (Cf. GUIMARÃES; DAVIES, 2018).

Nessa região também se localiza Realengo, quarto bairro mais populoso da cidade e onde próximo à estação de trem e à maior oferta de comércios e serviços há um grande lote administrado pelo Exército, cercado por muros e sem qualquer uso há mais de quatro décadas. Antes disso funcionou no terreno por 80 anos uma Fábrica de Cartuchos, e desde 2012 um grupo de moradores tem se organizado a favor da criação de um "parque verde", aproveitando o lote. Nos anos seguintes, ao expressar sua reivindicação através de estratégias de publicização e sensibilização, o "movimento" de moradores - tal como se

\footnotetext{
2 Ainda que tenha diferentes sentidos conceituais na literatura especializada, neste artigo o termo urbanismo recebe o significado usual de apanhado de questões que envolvem formas, organizações e evoluções das cidades e seus espaços.
} 
identificavam - logrou por parte das autoridades que administravam o terreno àquele momento, o comando da $1^{\text {a }}$ Região Militar ${ }^{3}$, apenas silêncios e respostas negativas a pedidos por encontros e negociações.

Em contraposição à proposta do grupo local, em 2015 o comando militar apresentou um projeto de repasse da área para investimento privado: a construção de um condomínio residencial por um banco ligado ao Exército foi a solução dada ao lote há anos abandonado. Por meio da assinatura de generais, um terreno em Realengo desliza de bem público a mais um produto do catálogo financeiro-imobiliário da cidade ${ }^{4}$.

Jogar luz à disputa em torno de uma área militar no Rio de Janeiro é parte de um esforço coletivo para compreensão das dinâmicas políticas no bojo da preparação para os megaeventos ${ }^{5}$, visto que, nesse contexto, decisões e contestações em relação aos espaços da cidade revelam as linhas de força que operaram na produção de "legados" urbanos ${ }^{6}$. Contudo, tomar esse conflito como parte da preparação da "região olímpica de Deodoro" só faz sentido ao se levar em conta o recorte realizado: na investigação para o doutorado explorei situações em Deodoro e bairros vizinhos que foram articuladas à realização dos Jogos por meio de estratégias de mobilização e ação coletiva que tomaram o evento como "ocasião-chave" para a realização das práticas às quais suas condutas eram direcionadas. Na situação envolvendo o terreno em Realengo, ações de moradores envolveram o projeto do condomínio aos Jogos de 2016 sob

\footnotetext{
${ }^{3}$ Segundo o Exército Brasileiro, as regiões militares têm funções administrativas e logísticas e desempenham pouca ou nenhuma responsabilidade operacional. São 12 regiões militares no país com um comando próprio e sediadas em capitais estaduais que circunscrevem as organizações militares da região. A $1^{\mathrm{a}}$ Região Militar engloba instalações situadas no Rio de Janeiro e no Espírito Santo.
}

${ }^{4} \mathrm{O}$ contexto de preparação do Rio de Janeiro para os megaeventos é também o de crescimento econômico e aquecimento imobiliário no país, quando o mercado imobiliário se integrou em grande parte às instituições financeiras. A "reestruturação imobiliária" concentrou a produção de imóveis na mão de poucas empresas e ampliou o alcance desses lançamentos para outras partes do Rio de Janeiro, como a região conhecida por subúrbio e a zona oeste. (Cf. SILVA, 2019).

${ }^{5}$ Pesquisas nas quais tenho me inserido e feito parte contribuíram para um entendimento mais amplo sobre a cidade e o momento dos megaeventos, entre as iniciativas menciono "Militarização e mercantilização da vida nas grandes cidades" (2018 - atual), coordenada pela Dra. Lia de Mattos Rocha e financiada pela FAPERJ, e "O Rio dos Megaeventos: Políticas Públicas e Efeitos Sociais" (20132017), coordenada pela Dra. Sandra de Sá Carneiro e financiada pela mesma instituição. Em diálogo com essas investigações, desenvolvi minha investigação de doutorado em Ciências Sociais, congraçada com Menção Honrosa do Prêmio de Melhor Tese 2018 da área de Sociologia (DAVIES, 2017).

6 Em convergência a outros trabalhos produzidos no período, tomo o "legado" como discurso e prática na preparação do Rio de Janeiro para os Jogos de 2016 e que, em anos anteriores, criou condições para a articulação entre agências e a reconfiguração de fronteiras da ação política. (Cf. MAGALHÃES, 2018). 
argumento de que aquele era um momento ótimo para negociações no mercado de terras e imóveis urbanos, e que, portanto, o interesse pela venda do lote e a construção de apartamentos eram propícios a esse cenário.

Envolvendo os comandos militares à especulação fundiária e incorporação imobiliária da cidade, o "movimento" inscreveu o conflito sobre o terreno às dinâmicas de produção da "região olímpica", e esse cruzamento entre tempos e espaços é o tema deste artigo. Tal recorte se inspira na perspectiva analítica que a socióloga Vera Telles $(2010,2013,2015)$ tem desenvolvido a respeito das "cartografias políticas das cidades" e suas dinâmicas por "linhas de força" que operam em processos de negociação e disputas situadas. Como o terreno de Realengo nos revela, comandos do Exército têm sido agentes de produção do espaço urbano, e o Rio de Janeiro dos megaeventos e Deodoro como "região olímpica" são casos bons pra pensar tal agenciamento. Nas próximas páginas são detalhados os alcances e possibilidades que autoridades das Forças Armadas têm encontrado para gestão de bens e imóveis públicos, recorrendo a brechas jurídicas que têm permitido a doação, a permuta e a venda de terrenos. Também exploro dados da pesquisa de campo que realizei entre 2013 e 2017 em Realengo, acompanhando e fazendo parte de um grupo de moradores mobilizados pela criação de um "parque verde" na antiga área militar. Delineando dinâmicas que envolveram diferentes agentes na condução desse projeto, coloco em discussão os sentidos de "público" atribuídos aos projetos de moradores organizados e autoridades do Exército.

\section{Áreas militares ou terrenos públicos: as "gambiarras" da cidade}

A situação de disputa envolvendo a área militar em Realengo se assemelha à de outros terrenos negociados pelos comandos do Exército com a Fundação Habitacional do Exército (FHE) e sua entidade mantenedora, a Associação de Poupança e Empréstimo (POUPEX). Essas entidades do sistema financeiro independentes do Exército estão vinculadas à Força pela atribuição legal à oferta de imóveis e financiamentos à moradia para integrantes da corporação; além disso, ambas são dirigidas por generais da reserva, expressando vínculos de continuidade entre essas instituições a despeito da autonomia administrativa e as diferenças de natureza jurídica que estabelecem com a corporação militar.

Entre as modalidades de oferta habitacional, além de crédito financeiro, a FHE dispõe de um catálogo imobiliário próprio, construído sob iniciativa do grupo. Esses condomínios e residenciais têm sido edificados em áreas militares cedidas ou permutadas com a instituição. Para tanto, a Fundação Habitacional e o 
respectivo banco têm recorrido à vigência de uma lei especial (n. 5.651) de 1970, por meio da qual o comando do Exército havia sido autorizado a realizar o repasse de imóveis "(...) cuja utilização ou exploração não atenda mais as necessidades" da corporação. No ano seguinte à promulgação dessa licença ao Exército, outra lei federal (n. 5.658) ampliou essa competência aos Ministérios da Marinha e Aeronáutica ${ }^{7}$.

A despeito de décadas passadas e da mudança de regime político e jurídico do país, decisões judiciais recentes a favor da validade dessas leis, como no caso de disputa em Realengo, expressam a reatualização das práticas autoritárias da ditadura civil-militar. No apagar de luzes desse período que se prolongou por mais de duas décadas (1964-1985), a FHE foi criada e subsidiada pela POUPEX, e dois anos depois de criação dessas entidades, outra lei (n. 7059) autorizou o comando do Exército "a doar, à Fundação Habitacional do Exército - FHE, bens imóveis da União, sob sua Jurisdição, cuja utilização ou exploração não atenda mais às necessidades do Exército", acrescentando que "os imóveis, quando postos à venda e permuta poderão ser oferecidos, antes de qualquer procedimento licitatório, a aquisição pela Fundação Habitacional do Exército".

Dessa forma, o aparato legal tem garantido não só a venda, mas também a dispensa de licitação à venda e permuta e até mesmo a doação de terrenos públicos para a entidade. Assim, a FHE/POUPEX eram contempladas como negociantes privilegiadas em situações de "desincorporação" de bens imóveis pelo Exército, com aval até mesmo à doação e dispensa de licitação para venda e permuta de imóveis públicos.

Por meio dessas transações entre Exército e FHE, autoridades militares têm conseguido vender terrenos públicos e também participar diretamente do investimento imobiliário realizado. A vigência legal dessas autorizações até os dias de hoje conforma esses generais como atores do capital urbano, desempenhando o papel de incorporadores fundiários nas cidades brasileiras. $\mathrm{Na}$ definição do cientista político Eduardo Marques, esse tipo de ator logra seus ganhos "(...) da sobrevalorização da terra pela mudança de uso, visto que a terra urbana não tem preço de produção e é um bem irreprodutível" (MARQUES, 2015, p. 18). Nesse sentido, incorporadores atuam orientados pela garantia de novos usos à terra, valorizando a localização e incrementando o lucro a partir das

\footnotetext{
7 A validade dessas orientações legais persiste em sentenças judiciais, apesar da extinção dos Ministérios que usufruíam dessas autorizações. Juízes que têm decidido a favor dessas medidas, segundo Gomes (2011), tem levado em conta os comandos superiores das corporações como os atores substitutos desses Ministérios, e não o Ministério da Defesa, que de fato substituiu esses ministérios militares desde 1999, quando foi criado. Para compreender o papel do Ministério e os desafios ao controle civil sobre as Forças Armadas no contexto de reabertura democrática, ver Zaverucha (2005).
} 
possibilidades de realização de novos projetos.

Na prática, a licença especial dada às corporações militares para a gestão de bens públicos é mantida a despeito da democratização política das últimas três décadas e do surgimento de novas regras para a administração do Patrimônio da União ${ }^{8}$. No caso desse terreno em Realengo, tal disputa vem ocorrendo há anos entre moradores e o comando da $1^{a}$ Região Militar, mas no período de preparação ao megaevento as estratégias de reivindicação foram sobressaltadas sob o boato de que o condomínio, enfim, "sairia do papel", aproveitando a valorização imobiliária e os investimentos em transporte e urbanização na região. Neste sentido, a intensificação da disputa se deu a partir de rumores a respeito de uma suposta decisão do comando militar naquele contexto. Em 2013, essa mobilização de moradores passou a vocalizar mais sua "causa", convocando a população e agregando novos integrantes, promovendo encontros regulares e divulgando eventos públicos.

A construção do primeiro residencial para correntistas da POUPEX $^{9}$ no país aconteceu no bairro e também gerou reivindicações por parte dos moradores. Ocupando outro lote da antiga Fábrica de Cartuchos, o Parque Real foi inaugurado em 1983 e motivou a formação de um grupo de moradores chamado Movimento Pró-Escola Técnica Federal da Zona Oeste. Naquele momento já se disputava o destino de áreas militares na vizinhança, neste caso sob a defesa de escolas públicas "de qualidade" na região. A contestação local persistiu no curso do tempo e gerou resultados: utilizando antigas áreas militares, em 2004 o Colégio Pedro II foi inaugurado no bairro e, em 2009, foi a vez do Instituto Federal do Rio de Janeiro (IFRJ) em 2009.

Apesar do sucesso desse movimento de moradores, o que tem prevalecido nas situações de disputa sobre áreas militares em desuso são as decisões dos comandos da corporação. Ao analisar casos julgados pelo Supremo Tribunal da Justiça, Gomes (2011) observou que a posição favorável à negociação dessas áreas era apoiada na "(...) necessidade de estas corporações terem uma autonomia que lhes proporcione os meios para o cumprimento de suas missões constitucionais em obediência ao interesse público - que poderá ser aferido a cada

\footnotetext{
8 Apesar da licença aos comandos militares para controle imobiliário, a Constituição de 1988 concentra a gestão desses bens na Secretaria de Patrimônio da União (SPU), não havendo outra instância ou autarquia governamental em nível federal licenciada à venda e outra negociação com o patrimônio público.

${ }^{9}$ Das três Forças Armadas, o sistema de financiamento habitacional do Exército é o único mediado por um banco privado e que contempla correntistas para além de militares da corporação. Este aspecto leva a considerar a finalidade pública e/ou estatal da realização desses projetos e deve ser contemplada e problematizada por esta pesquisa ao longo do seu desenvolvimento.
} 
remanejamento patrimonial que se possa ocorrer" (GOMES, 2011, p. 164). A "autonomia", neste caso, estaria "no espírito da Carta Magna" e por isso não seria divergente de outros princípios explícitos no documento.

Mais do que uma reatualização de práticas, a manutenção de leis de ordenamentos jurídicos ultrapassados opera como "gambiarra jurídica", arquitetando formas de governo através de "minúcias institucionais" instauradas como dispositivos de exceção - e de exceções que se tornam regras - desativando leis, garantias e direitos (TELLES, 2013). As "gambiarras", portanto, acionam dispositivos jurídicos sui generis e tomam por efeito o enfraquecimento dos preceitos constitucionais em voga, que no caso arbitrariam por outras instâncias deliberativas e por maior controle institucional sobre os processos de venda de terrenos públicos.

Ainda que não haja um levantamento das transações fundiárias operadas pelo Exército no Rio de Janeiro, é possível dizer que a cidade que concentra mais organizações militares no Brasil tem sentido o impacto do manejo fundiário pelos comandos da corporação especialmente no contexto de preparação para os megaeventos. Entre negociações recentes, foi feita em 2005 a transferência de propriedade de uma antiga área militar no Campinho, onde antes funcionava um regimento e um laboratório do Exército, para dar lugar a um hipermercado e um conjunto residencial. Ao longo de décadas, pequenos lotes em Realengo e Deodoro foram negociados com empresários locais (alguns legalmente, outros não), e em 2012 a Ilha de Bom Jesus foi vendida à multinacional General Electric, ao passo que outros terrenos foram permutados com a Prefeitura na preparação para os torneios esportivos: a hípica do Maracanã, o Parque de Deodoro e a área prevista para o autódromo são alguns exemplos, sendo que pouca ou nenhuma informação é divulgada quanto às condições dessas transferências e aos custos das operações. Entre todos os casos, a situação do projeto de autódromo em Deodoro talvez seja a que chama mais atenção: de acordo com o blog Olhar Olímpico, o Ministério dos Esportes teria pago 104 milhões de reais pela aquisição de um terreno de 2 milhões de metros quadrados administrado pelo Exército $^{10}$ (VECHIOLLI, 2019), ou seja, a movimentação de propriedade do bem público, ainda que estabelecida entre entidades da União, angariou receita considerável à corporação.

Mais do que "autonomia", as práticas de negociação fundiária têm se revelado um modus operandi dos comandos militares, que, a fins de exemplo, levou o Exército a arrecadar $\mathrm{R} \$ 115$ milhões com a venda e a permuta de terrenos entre

${ }^{10}$ Em reportagem citada, o jornalista comenta que "o conteúdo exato do Termo de Compromisso [firmado entre o Ministério dos Esportes e o Comando da 1a RM] não é de conhecimento público". 
2007 e $2011^{11}$. A permissão para transferência de terrenos públicos, outorgada com exclusividade a comandos da corporação e validada em recorrentes decisões judiciais, é prática reveladora da importância que essas autoridades ocupam na gestão das cidades brasileiras, indo além das situações tópicas de acionamento da "garantia da lei e da ordem", como se enfatiza nas análises sobre o tema. Casos de disputa sobre o espaço revelam que essas autoridades das Forças Armadas desempenham protagonismo como atores das políticas do urbano, no papel de incorporadores e vendedores do mercado fundiário-financeiro-imobiliário. Fora dos enquadramentos teóricos usuais sobre a mercantilização das cidades, contudo, esses personagens e suas práticas desafiam as investigações sobre o assunto.

Através de negociações envolvendo comandos do Exército, a fundação e o banco privado, permissividades jurídicas têm conduzido movimentações fundiárias nas cidades brasileiras. Em comum, essas organizações públicas e privadas têm sido dirigidas por oficiais superiores do Exército, o que permite afirmar que essas transferências de propriedade são um verdadeiro negócio entre esses senhores, um negócio de família e da "família militar". Disputando o terreno e o próprio sentido de "público", moradores têm contestado essas práticas e, ao mesmo tempo, explicitado e reivindicado outras alternativas em relação a esses agentes e projetos.

\section{Realengo Verde, parque ou condomínio?}

Estive pela primeira vez em uma das reuniões organizadas por moradores de Realengo em março de 2013. Na ocasião, eu e outras trinta pessoas soubemos que a reivindicação pelo uso da antiga área militar se desdobrava do Movimento PróEscola Técnica Federal da Zona Oeste e da iniciativa de alguns de seus integrantes: ainda em 2001, um ex-vereador e morador do bairro impetrou uma ação civil pública impedindo a derrubada de árvores no terreno; outra lei municipal de 2008, de sua autoria, definiu que a antiga área e suas dependências ficariam "garantidas para utilização de atividades públicas". De acordo com o ex-vereador, tal decisão legal ficaria vinculada à documentação do imóvel, e uma eventual tentativa de venda ou permuta da área seria inviabilizada por essa medida.

\footnotetext{
${ }^{11}$ FOLHA DE SÃO PAULO. "Venda de terras rende R\$114,4 mi a militares" (31/07/2011). Disponível em: www1.folha.uol.com.br/fsp/poder/po3107201104.htm. Acesso em: $1^{\circ}$ out. 2015.
} 
Apesar dos recursos a instrumentos jurídicos, naquela reunião os rumores alertavam sobre a necessidade de garantir efetivamente o uso da área para "atividades públicas", tais como previstas na lei municipal. Nos meses seguintes, a "vontade popular" foi alimentada ao mesmo tempo em que definida em seus termos, em um movimento de adesão e convencimento entre moradores do bairro e da vizinhança. Nos próximos meses daquele ano foram realizados vários eventos de rua, preenchidas dezenas de folhas de abaixo-assinado e divulgadas as reivindicações em meios de comunicação, como redes sociais, rádios comunitários e até mesmo veículos de imprensa. O grupo formado também insistiu de modo contínuo na busca por informações a respeito da situação legal do terreno e solicitou algumas vezes encontro com os generais responsáveis pela administração do lote; em contrapartida, jamais obtiveram respostas. Também não foram autorizadas visitas formais do grupo à área, nem obtido acesso a informações ou encontro com os oficiais. Se as mobilizações a partir de estratégias de publicização e sensibilização marcaram a conduta de moradores organizados, por outra parte os silêncios expressavam o modo como as autoridades militares lidavam com os moradores.

Apenas em julho de 2015 uma resposta concreta foi apresentada pelos generais, sinalizando o andamento do projeto do condomínio. Naquele momento, os muros altos da antiga área mais uma vez foram pintados de branco e receberam nova mensagem, grafada em preto em substituição ao tradicional aviso de "área militar". Em seu lugar estava por todo o lote: "Fundação Habitacional do Exército - FHE / Empreendimento Habitacional para integrantes das Forças Armadas".

Placas também sinalizavam o início da construção do residencial e trataram de caracterizar o condomínio; estava escrito: “o complexo habitacional contará com áreas públicas para a edificação de escolas, creche, comércio e parque urbano com espaço de lazer", ou seja, a divulgação do projeto era enfim realizada e, para espanto do movimento de moradores, a iniciativa da FHE absorvia em parte as vontades expressas na reivindicação por um "parque verde" com serviços públicos, tal como elaborado por eles.

No mês seguinte à divulgação do empreendimento, já constava na página virtual da Fundação Habitacional na seção de apresentação dos residenciais "em projeto". Para surpresa de todos, o condomínio também era chamado de "Realengo Verde", assim como o parque imaginado e divulgado pelo movimento de moradores em suas estratégias de publicização. A curta descrição no website confirmava essa aproximação, ou confusão, entre o projeto dos moradores e a iniciativa da FHE: este seria um complexo habitacional que, além de escolas e 
parque, também "irá gerar empregos e mais qualidade de vida para a comunidade da região de Realengo, no Rio de Janeiro/RJ".

O nome dado, tal qual o desejado pelos moradores, mimetizava o parque no próprio projeto de condomínio da FHE. Entre integrantes do movimento, a reação foi de espanto, surpresa e também de revolta. Para eles o projeto da Fundação pretendeu intencionalmente borrar - de verde - as diferenças entre as propostas de parque e residencial, dando a impressão de que a disputa havia sido perdida ou vencida, a depender de quem observasse o anúncio.

Repetindo o nome do parque, a FHE contribuiu para anular as reivindicações do movimento de moradores. Em encontros realizados à época, outro ofício do movimento solicitou dessa vez um encontro com os representantes da Fundação, mas o silêncio prosseguia, e tal reunião só foi realizada em dezembro daquele ano, a partir da mediação feita por um vereador ligado à Igreja Católica e do qual um dos moradores era também assessor parlamentar.

Na ocasião, um general da $1^{\text {a }}$ Região Militar e um oficial engenheiro ligado à obra da FHE compareceram ao encontro com moradores. Representantes do empreendimento enfatizaram o plano de uso misto do espaço, servindo à função pública como parque com duas escolas e uma creche. O plano do condomínio planejava a abertura de duas ruas no lote em formato de cruz, dividindo o terreno em quatro partes e permitindo o uso do eixo mais central com esse fim público. Detalhes da construção ainda não estavam certos, mas naquele encontro integrantes do movimento souberam que a estimativa era entre 1.200 e 1.300 unidades residenciais, divididas em dez edifícios.

Naquela reunião foi sabido que, por meio de uma portaria do comando da $1^{\text {a }}$ Região Militar expedida no dia 31 de dezembro de 2014, a propriedade da área havia sido transferida à FHE. Apesar da notícia, naquele momento moradores integrados ao movimento desacreditavam do valor legal dessa transferência, e por isso persistiram e ainda seguem persistindo na tentativa de encontrar novos embargos possíveis.

Ainda na reunião, o representante do comando militar lembrou que a região concentra o maior número de organizações militares da América Latina e que a FHE tem a função de prover casas aos militares. Nesse sentido, entendia haver uma "dívida" da corporação na oferta de moradias na região, pois muitos que trabalham/servem ali precisam alugar casas fora das áreas militares.

O oficial também tentou explicar como a Fundação "funciona", comprando terras que os comandos do Exército não têm interesse de usar e destinando seus usos a projetos de habitação financiados pelo banco. Afirmou que a área foi oferecida e paga por $\mathrm{R} \$ 5$ milhões, o que foi considerado irrisório por moradores, 
por ser um terreno de 142 mil metros quadrados, e que vai dar destino a mais de mil imóveis residenciais, como apresentado.

Diante dessas informações, novas ao movimento de moradores, as falas dos presentes recomendavam, de forma respeitosa, que as organizações do Exército buscassem outras áreas ao projeto, alegando que o contingente populacional do bairro já era muito alto e que ali não seria o melhor lugar para a iniciativa. Outros mesclavam esse pedido de mudança de endereço com elogios à presença dos representantes militares, ressaltando o respeito que nutriam pelos oficiais da corporação.

Nesse clima de cordialidade entre moradores e convidados, o oficial militar e o engenheiro da FHE ouviram todos sem responder a nenhum questionamento, tampouco se comprometendo com sugestões e pedidos. Ouvindo, mas ainda sem responder, o debate se estendeu até tarde, quando o vereador fez um encerramento inconcluso em que realçou o papel do parlamento na democracia. Para ele o parque poderia ser a solução para muitos problemas urbanos, mas é preciso "respeitar o Exército e a sua importância na sociedade". Na opinião do vereador, havíamos naquela reunião vivenciado "um encontro de fato democrático entre civis e militares".

Apesar do destino ainda hoje incerto, a situação de disputa em torno dessa área nos revela que os processos políticos que atravessam as cidades encontram em cada caso e contexto seus modos próprios de realização. No cotidiano urbano, experiências e condições locais tecem possibilidades de arranjos de poder e condução de condutas que, portanto, são situacionais e por tal motivo configuram tipos particulares daquilo que Marcia Leite (2015) tem chamado de "regimes territoriais".

Assim, o ordenamento jurídico vigente e as instituições formais da política não limitam as experiências de gestão das cidades nem a expressam em sua complexidade. Ao invés disso, a insuficiência dos pressupostos teóricos e conceituais nos impele a levar a sério os sentidos empíricos de "Estado" e "bem público", e parte deste artigo reflete esta questão. Analisar dinâmicas situadas de produção do espaço das cidades permite jogar luz sobre experiências práticas que explicitam as relações de poder escondidas sobre as formas urbanas (JACOBS, 2000). Tratar do tema do urbanismo militar pela perspectiva da disputa sobre terrenos públicos é, portanto, uma escolha teórica e metodológica que privilegia a compreensão sobre o papel desses agentes, seus modos de realização e os eventuais limites e alcances que encontram na disposição com os governados. Dessa maneira, tomar a produção do espaço sob esse prisma permite confrontar posições teóricas e alimentar novas referências conceituais e 
metodológicas para a discussão sobre as cidades e suas dinâmicas políticas.

\section{Considerações finais: para além dos megaeventos}

Um estudo sobre militares pode parecer estranho à discussão acadêmica sobre as cidades e a vida urbana em geral. Longe de ser um dado aleatório, essa estranheza reflete o próprio percurso das ciências sociais, em que o tema passou ao largo da nossa literatura clássica. Como indica Giddens (1991), apesar de a industrialização ter tido importante peso na produção de armas e de outros produtos militares, esse universo de questões não foi contemplada na obra de autores como Marx e Durkheim. Comprometida com uma leitura otimista sobre a modernidade, a Sociologia se firmou sob escolhas temáticas e também silêncios, motivos dos nossos estranhamentos quando tais discussões são trazidas à tona.

Tais silêncios operam na comunidade acadêmica até hoje, em particular nos países latinoamericanos. Segundo Carvalho (2005), pesquisadores têm reagido à presença de militares na cena política com omissão ou conivência, isso porque "(...) o tema não tem legitimidade acadêmica ou teórica, e é considerado suspeito do ponto de vista político" (op. cit., p. 140). Tal veto encontraria diferentes razões intelectuais: sob a vertente liberal, militares deveriam cumprir o papel de agentes sujeitos ao governo civil, e sob a vertente da esquerda tem sido enquadrados como força repressiva a serviço da classe dominante. Além disso, militares não se encaixam em esquemas tradicionais da Ciência Política, contribuindo para seu obscurecimento nas análises teóricas e empíricas sobre a política e sua realização nas democracias.

A despeito dos silêncios teóricos e investigativos, o momento atual parece crucial para se debater a participação militar na democracia brasileira. A partir da gestão Bolsonaro, iniciada em janeiro de 2019, presidente, vice-presidente, vários ministros, senadores, deputados federais e tantos ocupantes de cargos de chefia e confiança do governo federal são ou foram militares de carreira.

Representados como braço da violência legítima estatal, as forças de segurança e defesa têm se revelado mais do que isso. Em várias cidades brasileiras há intensa e dispersa presença territorial das Forças Armadas, implicando a coexistência e proximidade para ocupação e configuração dessas localidades. Também chamadas de "vilas militares", essas áreas que concentram instalações militares possuem modos de ordenamento e urbanização próprios (BONATES, 2016), que nos limites das instituições totalizantes (CASTRO, 2007) refletem conexões e conflitos com a vida civil e urbana.

No Rio de Janeiro pude acompanhar a preparação da "região olímpica de 
Deodoro" para a realização da minha pesquisa de doutorado (DAVIES, 2017, 2018), e nesse conjunto de bairros os comandos do Exército se revelaram atores importantes, e até mesmo protagonistas das dinâmicas associadas ao megaevento por conta do controle que realizam sobre organizações militares e áreas urbanas. Apesar disso, estudos acadêmicos dedicados à preparação e realização dos Jogos na cidade, ainda que tomados sob o ângulo do ciclo dos megaeventos, não consideraram em suas discussões os processos em curso na "região de Deodoro", optando por concentrar análises em pontos quentes, como a zona portuária renovada, a Barra da Tijuca sob forte aquecimento imobiliário, e as favelas sob jugo de projetos de "pacificação" e "integração" com a cidade. Reproduzindo silêncios teóricos, investigações atuais optaram por repetir enquadramentos conceituais e analíticos enquanto deixam escapar questões relevantes à compreensão das dinâmicas políticas da cidade, escondendo linhas de força da nossa cartografia política.

No caso da "região olímpica", a importância dessas autoridades não se ateve às infraestruturas dos Jogos, mas também aos efeitos associados ao evento como "legado". O parque verde, no caso do movimento de Realengo, foi a enunciação da vontade dos moradores para a antiga área militar, ao passo que o seu uso como condomínio privado era interpretado como oportunidade de negócio para os militares, motivados pela onda de especulação imobiliária daqueles anos. Por outro lado, os comandantes apresentaram seu projeto de moradia incorporando aspectos da vontade dos moradores, mantendo, entretanto, a transferência da área para a Fundação Habitacional.

$\mathrm{Na}$ negociação de terrenos públicos, o urbanismo militar conduzido por comandos da corporação tem se realizado com "autonomia" nas últimas décadas, a partir de preceitos jurídicos sui generis que sobrevivem na sobreposição às normas do novo ordenamento jurídico. Para tanto, além das "gambiarras jurídicas", os comandos militares têm lidado com essas práticas através da ausência ou insuficiência de divulgação de informações a respeito dos terrenos e das transações que realizam, quando as realizam. Entraves às interações com o movimento local de Realengo são reveladores das condutas unilaterais desses generais e dos modos autoritários com que escolhem lidar com os moradores civis, seus concidadãos.

Aproveitando privilégios legais e a falta de controle sobre suas ações, comandos militares têm decidido parte das dinâmicas espaciais das cidades brasileiras, além disso aproveitando as vendas diretas de investimentos imobiliários. O projeto de "região olímpica" na Vila de Militar de Deodoro redimensionou as configurações do espaço do Exército a partir das decisões dos 
seus comandos, concentrando investimentos em terras centrais já ocupadas por outras organizaçoes militares, próximas às vias de acesso, enquanto outros lotes, afastados desse eixo e vizinhos a bairros civis, eram negociados e repassados a organizações estatais e privadas. Os Jogos, portanto, se revelaram "ocasiãochave" para redefinir os modos de ocupação e uso das áreas militares em Deodoro e bairros vizinhos, seguindo com exclusividade os interesses do comando da corporação e, ao mesmo tempo, negando o diálogo com outros agentes, no limite, assimilando algumas reivindicações como forma de mitigar o conflito.

A forma de urbanismo militar, tal como seu agente, é desse modo autoritária ao desprezar formas de controle institucional e se fazer por medidas excepcionais vertida ao benefício de seus próprios realizadores. No limite com a vida civil das cidades, a produção do espaço sob essa lógica produz tensionamentos que colocam em risco a própria possibilidade de disputa política, abrindo nenhuma margem para outras intervenções e alternativas de realização. As razões e os impactos do urbanismo militar são muitos, e este artigo buscou tracejar aspectos desse debate a partir de uma situação-problema em um bairro do Rio de Janeiro, mas que transcende o caso ao marcar de forma perene as condições da democracia brasileira.

\section{Referências}

BONATES, Mariana Fialho.

(2016). Militares no Home Front: projetos urbanos e arquitetônicos das áreas residenciais militares brasileiras no segundo pós-guerra. Tese de doutorado apresentada ao Programa de Pósgraduação em Desenvolvimento Urbano da Universidade Federal de Pernambuco.

CARVALH0, José Murilo de.

(2005). Forças Armadas e política no Brasil. Rio de Janeiro: Jorge Zahar.

CASTRO, Celso.

(2007) Goffman e os militares: sobre o conceito de instituição total. 2007. Disponível em: https://www.academia.edu/19936225/Goffma n_e_os_militares_sobre_o_conceito_de_instit ui\% $\%$ C $\%$ A7\%C3\%A3o_total. Acesso em: mar. 2011.
DAVIES, Frank Andrew.

(2017). Deodoro: formas de governo para uma região olímpica. Tese de doutorado apresentada no Programa de Pós-graduação em Ciências Sociais da Universidade do Estado do Rio de Janeiro.

(2018). Formas de governo e conflitos com o Exército na produção da 'região olímpica de Deodoro'. In: LEITE, Marcia; ROCHA; Lia; FARIAS, Juliana; CARVALHO, Monique. (Org.). Militarização no Rio de Janeiro: da pacificação à intervenção. Rio de Janeiro: Mórula, 2018, v. 1, p. 39-59.

GOMES, Agnaldo Nogueira.

(2011). A competência do comando do Exército para alienar imóveis administrados pela força terrestre: a vigência da lei n. 5.651/1970 sob o ponto de vista da teoria da adequabilidade normativa. Monografia de especialização em 
Direito Administrativo apresentada ao Instituto Brasiliense de Direito Público, Brasília.

GIDDENS, Anthony.

(1991). As conseqüências da modernidade. São Paulo, UNESP.

GUIMARÃES, Roberta Sampaio \& DAVIES, Frank Andrew.

(2018). Alegorias e deslocamentos da categoria subúrbio carioca nos estudos das Ciências Sociais (1970-2010). Revista Sociologia \& Antropologia, Rio de Janeiro, v.08, n. 02, p. 457-482.

JACOBS, Jane.

(2000). Morte e vida das grandes cidades. São Paulo: Martins Fontes.

LEITE, Marcia Pereira.

(2015). De territórios da pobreza a territórios de negócios: dispositivos de gestão das favelas em contexto de 'pacificação' in: BIRMAN, Patricia et al. Dispositivos urbanos e trama dos viventes ordens e resistências. Rio de Janeiro, FGV/FAPERJ, p. 377-401.

MAGALHÃES, Alexandre.

(2018). Remoções de favelas no Rio Janeiro: entre formas de controle e resistências. Curitiba, Appris.

MARQUES, Eduardo.

(2015). Estado, atores políticos e governança. In: FERNADES, A. C et al. (orgs.). Desenvolvimento, planejamento e governança: expressões do debate contemporâneo. Recife, Ed. UFPE/IPEA/ANPUR, p. 181-201.

ROCHE, Maurice.

(2000). Mega-events and modernity: Olympics and expos in the growth of global culture. London: Routledge.
SILVA, Rafael Alves da.

(2019). Subúrbio S/A: reestruturação imobiliária e reconfiguração do espaço urbano carioca sob domínio do capital financeiro no século XXI. Dissertação de mestrado apresentada ao Programa de Pós-graduação em Arquitetura e Urbanismo da Universidade de São Paulo.

TELLES, Vera da Silva.

(2010). A cidade nas fronteiras do legal e ilegal. Belo Horizonte: Argvmentvm.

(2013). A gestão do conflito na produção da cidade contemporânea: a experiência paulista. Projeto temático. Fapesp [2014-2018].

(2015). Cidade: produção de espaços, formas de controle e conflitos. Revista de Ciências Sociais, n. 46, p. 15-42.

VECHIOLLI, Demetrio.

(2019). Área de autódromo do Rio tem imbróglio entre Exército, Esporte e Prefeitura. Disponivel em:

https://olharolimpico.blogosfera.uol.com.br/2 019/05/22/esporte-gastou-r-120-milhoespara-ter-terreno-de-futuro-autodromolimpo/?cmpid=copiaecola. Acesso em: 20 maio 2020.

ZAVERUCHA, Jorge.

(2005). A fragilidade do Ministério da Defesa brasileiro. Revista de Sociologia e Política, n. 25, p. 107-121.

Recebido em

dezembro de 2019

\section{Aprovado em}

agosto de 2020 